\title{
A case report of ring chromosome 18 with tetralogy of fallot
}

\author{
Sajjadian Negar ${ }^{\star, \dagger}, 1$, Herman Moghadam Kambiz ${ }^{2}$ \\ ${ }^{1}$ Associate professor, Pediatric ward, Tehran University of medical sciences, Tehran, Iran \\ ${ }^{2}$ Pediatrician, Tehran, Iran
}

DOI: https://doi.org/10.15520/ijmhs.v9i3.2492

Accepted 10 Mar 2019; Received 1 Feb 2019; Publish Online 28 Mar 2019

Reviewed By: Dr.
Daniel V.
Department: Medical

\begin{abstract}
Background: Ring Chromosome 18 is a rare chromosomal disorder with loss of genetic material from one or both ends of the 18th chromosome and fusion of the chromosomal ends to form a ring. Associated symptoms and physical features may be extremely variable.

Case report: we observed a 2.5 year old girl with the features typical for $r(18)$ carriers additionally manifested a Tetralogy of fallot. Chromosomal analysis on the basis of G-banding technique was performed. Chromosomal investigation appeared as 46, XY,r(18) (p11.31q22.3).

Conclusion: This information may help healthcare team make diagnosis a person with ring 18.
\end{abstract}

Key words: ring chromosome 18-hypothyroidism-tetralogy of fallot

\section{BACKGROUND}

Ring 18 happens when two tips of the chromosome 18 join together and form ring-shaped chromosome. During this process the tips of both the $\mathrm{q}$ and the $\mathrm{p}$ arms are deleted [1]. No two patients with ring 18 have the similar deletions of genetic materials. In Some cases there are only a little bit of missing genetic material without significant clinical manifestation, while others may have a considerable amount of missed genetic materials with severe clinical manifestations [2].

Most people with ring chromosome 18 have the ring chromosome in all of their body cell while, some people have some body cells with normal chromosomes. People with ring chromosome 18 mosaicism may have milder symptoms.

Depending on the amount of genetic material lost and which genes are involved, signs and symptoms that may be present in a person with ring chromosome 18 may vary. Clinical manifestations of ring chromosome 18 include ear and hearing abnormalities, abnormally-developed feet or hands, genital abnormalities in males, an increased risk to develop juvenile rheumatoid arthritis, holoprosencephaly, developmental delays, learning difficulties, short stature, and/or various birth defects. Many individuals with the dis-

* Corresponding author.

$\dagger$ Email: nsajjadian@yahoo.com. order manifest mental retardation, hypotonia; growth retardation; repeated episode of infections and/or craniofacial malformations [2, 3].

Females are affected slightly more than males. The diagnosis of ring Chromosome 18 is made before birth (prenatally) by specialized tests such as amniocentesis, and/or chorionic villous sampling (CVS) and diagnosed or confirmed after birth based upon a thorough clinical evaluation, detection of characteristic physical findings, and chromosomal analysis.

The treatment of Chromosome 18 Ring is based upon the specific symptoms that are apparent in each patient. This information may help healthcare team make diagnosis and how to care for a person. It is important to know that no two people with ring 18 are exactly alike.

In this deport we characterize a patient who apart from r(18) clinical manifestations exhibited Tetralogy of fallot ,a heart malformation usually not described in ring 18 cases.

\section{CASE REPORT:}

A2.5 year old girl, which was born by cesarean section at 38 weeks of gestation with birth weight of $2790 \mathrm{gm}$. She was the second child of a 34 year old mother and a 42 year old father. The patient was born to consanguineous Iranian healthy parents. Other sibiling was a 13 -year -old girl 
who was healthy. At birth she had cleft lip, microcephaly, rocker bottom feet, overriding second and third fingers, high arched palate and a systolic murmur was auscultated. Tetralogy of fallot was detected in cardiac echocardiography. After discharge from hospital ,patient had high TSH level in neonatal screening program $(\mathrm{TSH}>100 \mathrm{micIU} / \mathrm{ml}$ at 17 day of age).

She suffered from repeated episode of urinary tract infections, chronic otitis media, feeding disabilities and poor weight gain during the infancy. Patient had failure to thrive (present weight $=7200 \mathrm{gm}$, Head Circumference $=41 \mathrm{~cm}$, Length $=78 \mathrm{~cm}$ ).

She have global delay of development especially in language ability (she can say only 3 words at 2.5 year of age) and acquired waking ability at 2 year of age. At 2.5 year of age her average abilities are equal to a 12 month old child, fine motor 12 months, personal-social aspect was 14 month, language 12 months and gross motor 18 months.

In the presented patient growth hormone studies and Brain MRI were not done due to parental refusal. Tympanogram was done that showed bilateral type B hearing impairment in favor of chronic otitis media.

Chromosomal analysis was performed according to standard procedures using $\mathrm{G}$-banding. Twenty metaphase cells were studied on the basis of $\mathrm{G}$-Banding technique at the 450-500 bands resolution. All cells revealed 46 chromosomes. Ring chromosome 18 in one of homologous 46, XX, r (18) (p11.31 q22.3) was seen in all metaphase cells. (Figure 1), whereas the parents karyotype appeared normal (46, $\mathrm{XX}$ and $46, \mathrm{XY}$ ), so this abnormality was proved by chromosomal study.

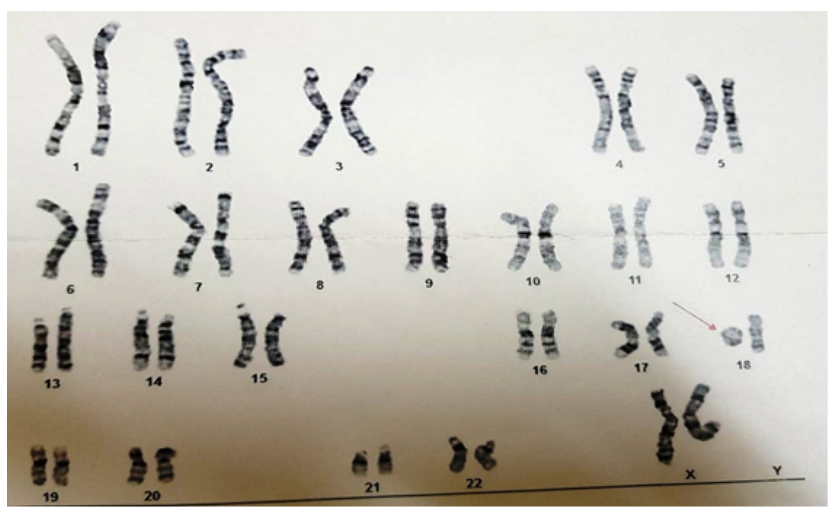

Figure 1.

\section{DISCUSSION:}

Ring chromosome 18 [r (18)] is a relatively rare chromosomal abnormality characterized by the replacement of a normal chromosome 18 by the ring chromosome. A ring formation is usually accompanied by the partial loss of genetic material from both ends of 18 chromosome. Variable clinical manifestation depends on the extend of the deleted genetic materials on the ends of chromosome 18. [4]
The patients with ring 18 usually have similar phenotypic features to $18 \mathrm{p}$ deletion syndrome [5] or $18 \mathrm{q}$ deletion syndrome [6] or a combination of both features [7] including mental retardation, hypotonia, short stature, microcephaly, speech delay, facial anomalies [8,9]. Our patient revealed a phenotype similar with other reported cases, with both 18 $\mathrm{p}$ and $18 \mathrm{q}$ deletion syndrome. The most interesting finding in our case was tetralogy of fallot which had not been mentioned in previous case reports .

Tetralogy of Fallot has been linked to a specific region on $18 \mathrm{p}$. This is a specific type of heart defect that is composed of four different changes in the heart's anatomy. In a research published by the Chromosome 18 Clinical Research Center, $7 \%$ of people that are missing this critical region have this heart defect [10]. Because heart defects are more common in babies with ring 18 than in those without ring 18, an echocardiogram may be recommended to look for defects.

People who are missing this region of chromosome 18(72,379,769-76,526,497) show increased risk for clefts, specifically, cleft lips and palates. Cleft lip and palate may lead to dental, hearing, speech, and feeding problems. [11, 12]

Kidney problems have been linked to deletions of chromosome 18. Several different types of kidney problems have been reported in children with ring 18. Incomplete Urine empting results in an abnormal accumulation of urine in the urinary system. This may lead to repeated urinary tract infections. [11, 12]

Children may demonstrate changes in their growth patterns. Children with ring 18 are often small for their age(SGA). Growth hormone deficiency has been linked to both $18 \mathrm{p}-$ and $18 \mathrm{q}-$; identified in some people with ring 18 , however , the precise frequency of this finding is unknown. In addition to short stature, many people with ring 18 have microcephaly. [11, 12]

\section{CONCLUSION:}

We present a patient with a phenotype similar to both $18 \mathrm{p}$ and $18 \mathrm{q}$ deletion and ring chromosome 18 combined with Tetralogy of fallot.

Conflicts of Interest

None of the authors have any competing interests in the manuscript.

\section{REFERENCES}

[1] J, A H, KB H. et al. Ring chromosome formation as a novel escape mechanism in patients with inverted duplication and terminal deletion. European journal of human genetics Eur J Hum Genet 2007;15:548-55.

[2] Dobos M, Feket G, Raff R. et al. Ring chromosome 18: clinical, cytogenetic and molecular genetic studies on four patients. Int J Hum Genet;4:197-200.

[3] Lo-Castro A, El-Malhany N, Galasso C. novo mosaic ring chromosome 18 in a child with mental retardation, epilepsy and immunological problems. Eur J Med Genet;54:329-32. 
[4] Thies U, et al. Prenatal diagnosis and fetopathological findings in a fetus with ring chromosome 18. Fetal Diagn Ther; 1998.

[5] Bird LM, Pretorius DH, Mendoza AE, Jones MC. Anencephaly with holoprosencephalic facies due to ring chromosome 18. Clin;6:351-8.

[6] Meloni A, Boccone L, Angius L, Loche S, Falchi AM, Cao A. Hypothalamic growth hormone deficiency in a patient with ring chromosome 18. Eur J Pediatr;153:110-2.

[7] Nakayama J, Hamano K, Shimakura Y, Iwasaki N, Nakahara C, Imoto N. Abnormal myelination in a patient with ring chromosome 18. Neuropediatrics; 1997.

[8] Christensen KR, Friedrich U, Jacobsen P, Jensen K, Nielsen J, Tsuboi T. Ring chromosome 18 in mother and daughter. J Ment Defic Res;14:49-67.

[9] Dacou-Voutetakis C, Sertedaki A, Maniatis-Christidis M, Sarri C, Karadima G, Petersen MB. et al. Insulin dependent diabetes mellitus (IDDM) and autoimmune thyroiditis in a boy with a ring chromosome 18: Additional evidence of autoimmunity or IDDM gene(s) on chromosome 18. J Med Genet;36:156-8.

[10] H ZOGAJM, C SEBOLD, P HEARD. ,et al. A Review of 18p Deletions American. Journal of Medical Genetics Part C (Seminars;in Medical Genetics) ,2015.169C:251-264.

[11] United States National Library of Medicine and National Institutes of Health. Chromosome 18p deletion syndrome, multiple congenital anomaly/ mental retardation (MCA/MR) syndromes;. Available from: ttp://www.nlm. nih.gov/mesh/jablonski/syndromes/syndrome.

[12] United States National Library of Medicine and National Institutes of Health. Chromosome 18q deletion syndrome, multiple congenital anomaly/ mental retardation (MCA/MR) syndromes;. Available from: http://www.nlm.

\section{AUTHOR BIOGRAPHY}

Sajjadian Negar Associate professor, Pediatric ward, Tehran University of medical sciences, Tehran, Iran

Herman Moghadam Kambiz Pediatrician, Tehran, Iran 